\title{
Article \\ Highly Sensitive Immunoresistive Sensor for Point-Of-Care Screening for COVID-19
}

\author{
Tianyi Li ${ }^{1}$, Scott D. Soelberg ${ }^{2}$, Zachary Taylor ${ }^{1}$, Vigneshwar Sakthivelpathi ${ }^{1}$, Clement E. Furlong ${ }^{2}$, \\ Jong-Hoon Kim ${ }^{3}{ }^{\mathbb{D}}$, Sang-gyeun Ahn ${ }^{4}$, Peter D. Han ${ }^{5,6}$, Lea M. Starita ${ }^{5,6}$, Jia Zhu ${ }^{7} \mathbb{D}$ and Jae-Hyun Chung ${ }^{1, *}$ \\ 1 Department of Mechanical Engineering, University of Washington, Seattle, WA 98195, USA; \\ lit24@uw.edu (T.L.); zntaylor@uw.edu (Z.T.); viggysak@uw.edu (V.S.) \\ 2 Departments of Medicine, Division of Medical Genetics and Genome Sciences, University of Washington, \\ Seattle, WA 98195, USA; scottjs@uw.edu (S.D.S.); clem@uw.edu (C.E.F.) \\ 3 School of Engineering and Computer Science, Washington State University, Vancouver, WA 98686, USA; \\ jh.kim@wsu.edu \\ 4 Industrial Design, University of Washington, Seattle, WA 98195, USA; ahnsang@uw.edu \\ 5 Department of Genome Sciences, University of Washington, Seattle, WA 98195, USA; \\ petedhan@uw.edu (P.D.H.); lstarita@uw.edu (L.M.S.) \\ 6 Brotman Baty Institute for Precision Medicine, Seattle, WA 98195, USA \\ 7 Department of Laboratory Medicine and Pathology, University of Washington, and Vaccine and Infectious \\ Disease Division, Fred Hutchinson Cancer Research Center, Seattle, WA 98195, USA; jiazhu@uw.edu \\ * Correspondence: jae71@uw.edu; Tel.: +1-206-543-4355
}

Citation: Li, T.; Soelberg, S.D.; Taylor, Z.; Sakthivelpathi, V.; Furlong, C.E.; Kim, J.-H.; Ahn, S.-g.; Han, P.D.; Starita, L.M.; Zhu, J.; et al. Highly Sensitive Immunoresistive Sensor for Point-Of-Care Screening for COVID-19. Biosensors 2022, 12, 149. https://doi.org/10.3390/ bios12030149

Received: 19 January 2022

Accepted: 24 February 2022

Published: 28 February 2022

Publisher's Note: MDPI stays neutral with regard to jurisdictional claims in published maps and institutional affiliations.

Copyright: (c) 2022 by the authors. Licensee MDPI, Basel, Switzerland. This article is an open access article distributed under the terms and conditions of the Creative Commons Attribution (CC BY) license (https:// creativecommons.org/licenses/by/ $4.0 /)$.

\begin{abstract}
Current point-of-care (POC) screening of Coronavirus disease 2019 (COVID-19) requires further improvements to achieve highly sensitive, rapid, and inexpensive detection. Here we describe an immunoresistive sensor on a polyethylene terephthalate (PET) film for simple, inexpensive, and highly sensitive COVID-19 screening. The sensor is composed of single-walled carbon nanotubes (SWCNTs) functionalized with monoclonal antibodies that bind to the spike protein of SARS-CoV-2. Silver electrodes are silkscreen-printed on SWCNTs to reduce contact resistance. We determine the SARS-CoV-2 status via the resistance ratio of control- and SARS-CoV-2 sensor electrodes. A combined measurement of two adjacent sensors enhances the sensitivity and specificity of the detection protocol. The lower limit of detection (LLD) of the SWCNT assay is 350 genome equivalents $/ \mathrm{mL}$. The developed SWCNT sensor shows $100 \%$ sensitivity and $90 \%$ specificity in clinical sample testing. Further, our device adds benefits of a small form factor, simple operation, low power requirement, and low assay cost. This highly sensitive film sensor will facilitate rapid COVID-19 screening and expedite the development of POC screening platforms.
\end{abstract}

Keywords: single-walled carbon nanotubes; immunoresistive sensor; resistance ratio; COVID-19; point-of-care diagnosis

\section{Introduction}

The emerging SARS-CoV-2 virus, including its reemerging coronavirus variants, continues to pose a serious threat to global public health and economy. As of 3 January 2022, the World Health Organization (WHO) reported worldwide 281,808,270 confirmed cases, including a total of 5,411,759 deaths due to SARS-CoV-2 infection caused Coronavirus Disease 2019 (COVID-19) [1]. The novel coronavirus has impacted industry, economy, and many facets of our daily life. Currently, COVID-19 continues to spread rapidly in communities around the world.

The diagnosis of COVID 19 is based on respiratory system assessment, nucleic acidbased method, and immunoassays. Respiratory system assessment, such as chest CT and wearable breath monitoring, lacks specificity [2,3]. Alternatively, respiratory rate, oxygen saturation, and heart rate are used for symptom management [4]. For an accurate diagnosis, nucleic acid amplification tests (NAATs) such as quantitative reverse 
transcription-polymerase chain reaction (qRT-PCR) assay [5,6] are considered the gold standard for COVID-19 screening [7]. These methods are currently used for screening patients for COVID-19 infection. However, these commercial assays require $4 \sim 6 \mathrm{~h}$ of assay time, as well as expensive, bulky equipment and skilled technicians [8]. More recently, a loop-mediated isothermal amplification (LAMP) assay has been developed to accelerate the screening. By combining a shorter screening time with a more convenient detection tool such as colorimetry, a POC NAAT detection assay could be developed. For example, a colorimetric reverse-transcriptional LAMP assay was developed for the detection of SARS-CoV-2 [9].

Many rapid tests have been developed to detect whole virus, viral RNA, immunoglobulin from infection, and antigens without nucleic acid amplification [10]. For example, the volatile organic compounds (VOCs) of exhaled gas could be detected for screening [11]. Among these, many commercially available rapid tests detect antigens. For example, lateral flow immunoassays (LFIA) rely on fluorescent, colorimetric, or electrochemical detection methods to detect the presence of SARS-CoV-2 viral proteins. Such antigen tests are being used as pre-screening or home screening tools under the Emergency Use Authorization (EUA) [12]. These devices are simple, fast, and low cost but are limited to sensitivity. The BinaxNOW ${ }^{\mathrm{TM}}$ COVID-19 Antigen Self Test was reported to have a lower limit of detection (LLD) of $10^{4}$ copies $/ \mathrm{mL}$, which is 100 -fold less sensitive than qRT-PCR tests [13]. Other Ag-based commercial POC antigen tests have a limit of detection (LOD) greater than $10^{6}$ copies $/ \mathrm{mL}$ [14]. These reported levels are not sensitive enough to detect the target virus in nasal swab samples at an early stage of infection where the viral load can be lower than 100 copies $/ \mathrm{mL}$, according to a clinical study [15]. Immunoglobulin tests detecting Immunoglobulin G (IgG) or Immunoglobulin M (IgM) lack specificity, do not respond to early-stage infection, and may produce false positives for the vaccinated population [16-18]. Other detection methods are more promising in accuracy and screening time. Some of them are antibody-coated field-effect transistors [19,20], paper-based electrochemical sensors [21], nanoparticles (NP) based electrochemical sensors [22], optical sensors [23], surface plasmon resonance (SPR) [24], and surface-enhanced Raman spectroscopy (SERS) [25].

Single-walled carbon nanotubes (SWCNTs) are one of the potential candidates for simple and inexpensive detection with high sensitivity and specificity. Resistive SWCNT sensors can detect target binding by electrostatic interaction or work function modification [26-29]. Viral particles and bacteria can be detected by monitoring this resistance change. Using similar technology, the LLD of the swine influenza virus (H1N1) was 177 TCID50 (50\% tissue culture infective dose)/ $\mathrm{mL}$ [30]. SWCNTs functionalized with heparin detected dengue virus at concentrations as low as $840 \mathrm{TCID} 50 / \mathrm{mL}$ [31]. For detecting $\mathrm{H} 1 \mathrm{~N} 1$, the LLD was 1 plaque-forming unit (PFU)/mL [32]. In our previous report, Mycobacterium tuberculosis (MTB) was detected at $100 \mathrm{CFU} / \mathrm{mL}$ in sputum samples using SWCNT sensors combined with magnetic particles [33]. However, this assay did not demonstrate sufficient sensitivity for detecting early-stage SARS-CoV-2 patients. Also, because the sensor substrate was made on silicon chips, the fabrication and integration costs were too high for an inexpensive screening assay.

In this paper, we constructed a resistive SWCNT biosensor on a polyethylene terephthalate (PET) film for low-cost COVID-19 screening. An array of silver electrodes were silkscreen-printed on SWCNTs for large-scale production. The sensitivity and specificity were characterized for SARS-CoV-2 in phosphate-buffered saline (PBS) and nasal swabs. The relative resistance ratio of both control and sensor was measured upon binding of the spike protein of SARS-CoV-2. The SWCNT sensor also detected the virus in positive nasal swabs previously screened with qRT-PCR. The presented biosensor will facilitate the development of a POC COVID-19 rapid screening platform that has high sensitivity, low assay cost, and low power requirements. 


\section{Materials and Methods}

\subsection{Sensor Configuration and Operation}

The SWCNT immunosensor was designed to handle a minimally processed nasal swab sample suspended in $1 \mathrm{~mL}$ of PBS, yielding a 'Yes or No' answer. The prototype device (Figure 1a) was composed of two linear motors for vertical sensor movement (dipping, withdrawal, and rinsing) and horizontal sample cup movement (solution change and mixing). Resistance was measured for both sensor and control electrodes. A heater was embedded under a sample cup to maintain a temperature of $36^{\circ} \mathrm{C}$ to speed up the antibody-antigen binding and maintain a consistent temperature through the assay steps and between samples.

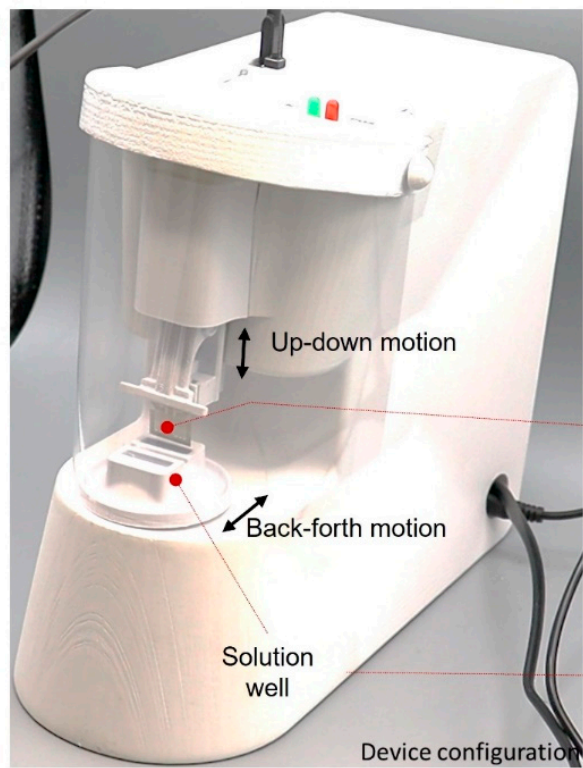

b) PET film

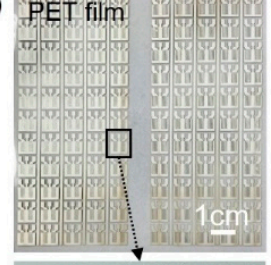

c) Sensor

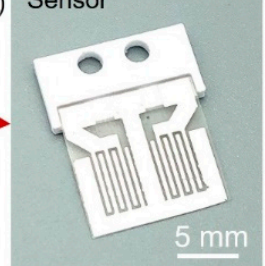

d)

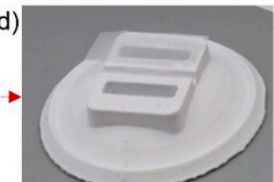

e)

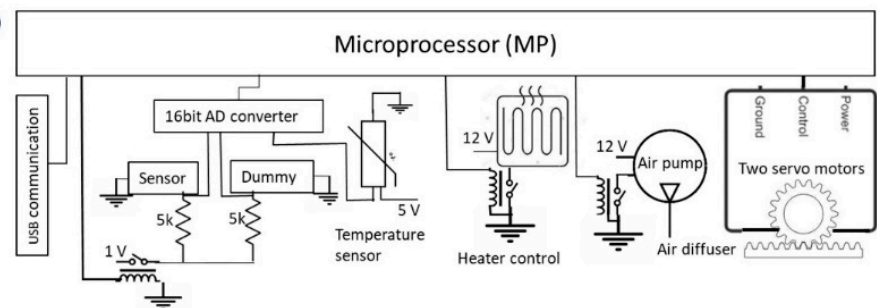

Figure 1. (a) Analyzer for rapid COVID-19 screening. (b) Sensors are made on a PET film coated with single-walled carbon nanotubes immobilized with antibodies. (c) A sensor consists of a SARS-CoV-2 sensor and a control sensor. (d) Sample cup containing $1 \times$ PBS with $1 \mathrm{~mL}$-target analyte and $1.1 \mathrm{~mL}-\mathrm{DI}$ water. (e) Configuration of the electric circuit. USB communication unit, resistance measurement units, temperature sensing unit, heating and control unit, air blow with a diffuser, and two servo motors for vertical and horizontal movements.

The SWCNT sensor was fabricated by spin-coating SWCNTs onto a PET film and silkscreening silver electrodes over the SWCNT surface (Figure 1b). A SWCNT sensor was composed of a sensing electrode and a control electrode (Figure 1c). The SWCNTs on the sensing electrode were covalently conjugated with monoclonal antibodies specific to the spike protein of SARS-CoV-2. The SWCNTs on the control electrode element were conjugated with bovine serum albumin (BSA). The interdigitated electrodes offered a large surface area for high sensitivity.

The sample cup had two liquid compartments: one held $1 \times$ PBS from a nasal swab sample, and the other held deionized (DI) water for the washing steps (Figure 1d). For immunocomplex formation, a buffered solution (PBS) was needed. Since the electrostatic 
interaction of SWCNTs with antigen was a key mechanism for detection, the masking effect by ions in the PBS needed to be reduced by rinsing the sensor with DI water. The vertical motion of the sensor played two roles in detection. One was to eliminate nonspecific binding, and the other was to rinse and dry the sensor completely. By carefully controlling the sensor withdrawal step, the capillary and viscous forces removed the nonspecifically bound molecules.

The sensor surface was mostly dried by using a low withdrawal speed $(1 \mathrm{~mm} / \mathrm{s})$. The remaining water drop at the edge of the sensor surface was removed by an air diffuser designed to blow air uniformly over the sensor surface. An air pump (flow rate: $4 \mathrm{~L} / \mathrm{min}$ ) was connected to the air diffuser, which was powered on only at the withdrawal step. The air pump operated at a low flow rate so that aerosols could not be generated but the sensor surface could completely dry. The resistance measurement confirmed the complete dryness of the sensor surface. A sensor with residual water yielded low and unpredictable resistance readings, while a dry sensor showed stable values. If a sensor remains wet, the silver electrode on the sensor surface could be quickly oxidized due to the potential.

Figure 1e shows the configuration of the control and electrical units, including a microcontroller (Atmega 328p). The resistance measurement units were installed to measure the resistance change of the sensor elements. A joule heating element with a temperature sensor was installed to maintain the temperature between 35 and $37{ }^{\circ} \mathrm{C}$. An air pump was controlled with a relay switch. Two servo motors were combined with a rack and pinion gear to provide accurate linear movements.

The major innovation of the SWCNT sensor was to use the ratio of the resistance change of a sensing electrode in comparison to that of a control electrode. In our previous work [33], the sensing mechanism was characterized. Despite the high sensitivity, the previous sensor was susceptible to temperature change and aging. In this SWCNT sensor, such effects could be calibrated by comparing the resistance change of sensing and control electrodes. Based on the comparison, we could identify the subtle resistance change from the target binding by negating environmental changes.

The use of PET films as sensor substrates significantly reduces the material and manufacturing costs in comparison to silicon chips. However, the rough surface on a PET film made the contact resistance higher. According to our study previously performed using an atomic force microscope, the roughness of the surface ranges from 15 to $80 \mathrm{~nm}$. By patterning silver electrodes on the SWCNT surface, the contact resistance could be stably controlled [33].

For the screening protocol, a swab was used to collect a sample from inside the nostrils (Figure 2). The sample swab was then immersed and stirred in $1.2 \mathrm{~mL}-1 \times \mathrm{PBS}$. A sample cup containing $1.1 \mathrm{~mL}$-DI water was installed in the analyzer. One $\mathrm{mL}$ of the $1 \times \mathrm{PBS}$ solution containing the swab sample was then transferred to the sample cup. After sensor installation, the 15 min-screening protocol was initiated. Once the measurement was completed, the data were analyzed and transferred to a laptop computer. 


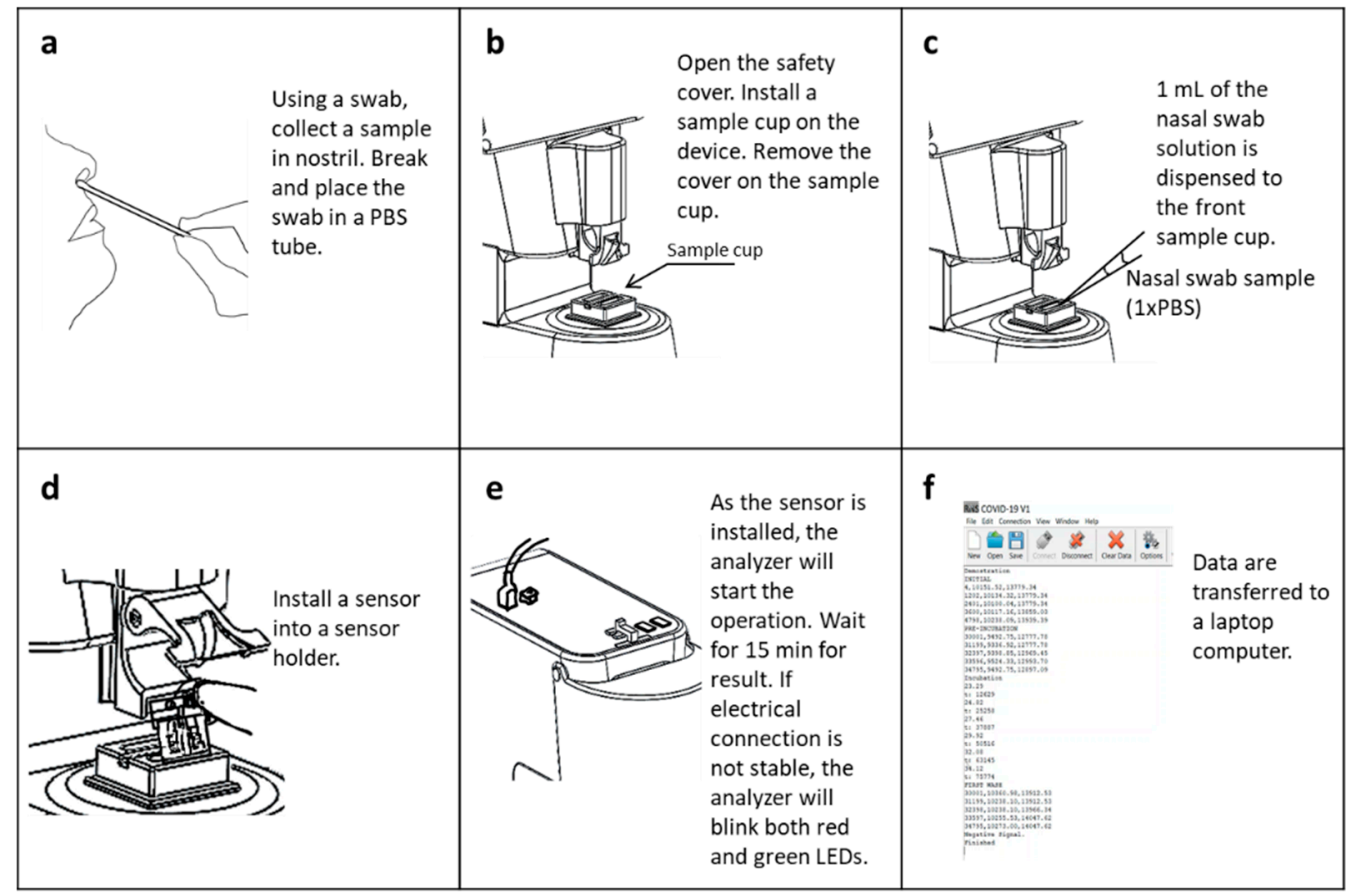

Figure 2. Screening protocol (a) Nasal swab sample is collected from nostril. The nasal swab is immersed and eluted in $1 \times$ PBS. (b) Install a sample cup where $1.1 \mathrm{~mL}$ DI water is contained. (c) A nasal swab sample of $1 \mathrm{~mL}$ is transferred to a sample cup. (d) Install a sensor with inspection of electrical connection. (e) Press a reset switch to begin detection protocol. (f) Data are collected after $15 \mathrm{~min}$.

For the screening protocol, the resistances of the sensing and control electrodes were measured five times during the course of one assay. The resistance measurement steps are described with the detection protocol in Table 1. At the initial stage, the resistances of the sensing and control electrodes were measured $\left(R_{0_{-} s}\right.$ and $\left.R_{0 \_}\right)$. Subsequently, the sensor was immersed into the DI water for 10 seconds, withdrawn, and dried with an air pump for $40 \mathrm{~s}$. The resistances were measured after air dry with an average of five readings $\left(R_{1 \_s}\right.$ and $\left.R_{1 \_c}\right)$. The resistance values from DI water showed the initial status of SWCNT sensors. If the ratio $\left(\mathrm{P}_{1}=\mathrm{P}_{1 \_\mathrm{s}} / \mathrm{P}_{1 \_\mathrm{c}}\right)$ was in the range of $0.9 \sim 1.1$, the measurement went to the next step. If the ratio was not in the range, the screening was halted due to poor sensor functionality. Once the quality control step passed, the sensor was then dipped into the sample cup containing the nasal swab sample in $1 \mathrm{~mL}$ of $1 \times \mathrm{PBS}$. The sensor was agitated in this sample at a speed of $1 \mathrm{~mm} /$ second back and forth for 10 min with the liquid temperature at $36{ }^{\circ} \mathrm{C}$. After a $10 \mathrm{~min}$ incubation, the sensor was rinsed in the DI water well at a stirring speed of $2 \mathrm{~mm} / \mathrm{s}$ for $10 \mathrm{~s}$. The sensor was subsequently air-dried, and the resistance values of $R_{2 \_s}$ and $R_{2 \_c}$ were measured. The same dipping rinse steps were repeated without stirring twice, during which a set of $\left(R_{3 \_s}, R_{3 \_c}\right)$ and $\left(R_{4 \_s}, R_{4 \_} c\right)$ was measured. 
Table 1. Screening protocol, resistance measurement, parameters, and screening time.

\begin{tabular}{|c|c|c|c|}
\hline $\begin{array}{c}\text { Resistance } \\
\text { Measurement Step }\end{array}$ & $\begin{array}{l}\text { Resistance Values } \\
\text { and Ratios }\end{array}$ & Parameters & $\begin{array}{l}\text { Time (minutes) } \\
\text { Total Time = } 15 \mathrm{~min}\end{array}$ \\
\hline Before testing & $\begin{array}{l}P_{0 \_s}=R_{0 \_s} / R_{0 \_s} ; \\
P_{0 \_c}=R_{0 \_c} / R_{0 \_c}\end{array}$ & $P_{0}=P_{0 \_s} / P_{0 \_c}=1$ & 0.5 \\
\hline Prewash in DI water & $\begin{array}{l}\mathrm{P}_{1 \_\mathrm{s}}=\mathrm{R}_{1 \_\mathrm{s}} / \mathrm{R}_{0 \_\mathrm{s}} \\
\mathrm{P}_{1 \_\mathrm{c}}=\mathrm{R}_{1 \_\mathrm{c}} / \mathrm{R}_{0 \_\mathrm{c}}\end{array}$ & $P_{1}=P_{1 \_s} / P_{1 \_c}$ & 1 \\
\hline Incubation & Not Measured & None & 10 \\
\hline Wash 1 & $\begin{array}{l}P_{2 \_s}=R_{2 \_s} / R_{0 \_s} ; \\
P_{2 \_c}=R_{2 \_c} / R_{0 \_c}\end{array}$ & $P_{2}=P_{2 \_s} / P_{2 \_c}$ & 1 \\
\hline Wash 2 & $\begin{array}{l}P_{3 \_s}=R_{3 \_s} / R_{0 \_s} ; \\
P_{3 \_c}=R_{3 \_c} / R_{0 \_c} c\end{array}$ & $P_{3}=P_{3 \_s} / P_{3 \_c}$ & 1 \\
\hline Wash 3 & $\begin{array}{l}\mathrm{P}_{4 \_s}=\mathrm{R}_{4 \_s} / \mathrm{R}_{0 \_s} ; \\
\mathrm{P}_{4 \_\mathrm{c}}=\mathrm{R}_{4 \_\mathrm{c}} / \mathrm{R}_{0 \_\mathrm{c}}\end{array}$ & $\mathrm{P}_{4}=\mathrm{P}_{4 \_\mathrm{s}} / \mathrm{P}_{4 \_\mathrm{c}}$ & 1 \\
\hline
\end{tabular}

Regarding the quality control step, the initial resistance measurement was used to find the functionalization quality of a sensor in comparison to control. It was found that the errors were caused by the activation and deactivation step of the carboxyl group on the SWCNT surface. The errors could occur due to small differences in the manual fabrication steps, including pipetting and incubation steps. In our test, the fabrication yield was $\sim 70 \%$. In the future, quality control needs to be improved to increase the fabrication yield.

\subsection{Sensor Fabrication}

An SWCNT sensor was prepared by screen-printing silver electrodes on an SWCNT-coated polyethylene terephthalate (PET) substrate (Figure 3a). Polyethyleneimine solution (0.1\% PEI in DI water) was prepared by diluting a stock solution (50\%, Millipore-Sigma, St. Louis, MI, USA). The diluted PEI solution was spin-coated on a $100 \mu \mathrm{m}$-thick PET film (3M Highland 903) at $3000 \mathrm{rpm}$ for $3 \mathrm{~min}$. SWCNTs were spread on the PET surface $\left(200 \times 200 \mathrm{~mm}^{2}\right)$. Using a radius of $100 \mathrm{~mm}$, the relative centrifugal field (RCF) was $1006 \mathrm{~g}$. The spin-coater we used was VTC-50A (MTI Corporation, Richmond, CA, USA). The PEI-coated film was cured at $100^{\circ} \mathrm{C}$ for $10 \mathrm{~min}$. Carboxylic acid-functionalized SWCNTs (SWCNT-COOH, Millipore-Sigma) were dispersed in double-distilled water ( $\mathrm{ddH}_{2} \mathrm{O}$, Millipore-Sigma) at $0.3 \mathrm{mg} / \mathrm{mL}$. Using a horn-type sonicator, SWCNTs were dispersed for $20 \mathrm{~min}$. The SWCNT suspension was spin-coated on a PEI-coated PET film at $3000 \mathrm{rpm}$ for $3 \mathrm{~min}$, followed by curing at $100{ }^{\circ} \mathrm{C}$ for $10 \mathrm{~min}$. Silver ink was used to silkscreen electrodes onto the SWCNT-coated sensor surface. The silver we used was AG-510 conductive ink (Kayaku Advanced Materials, Westborough, MA, USA). The screen printer was the LS-34 (New Long, Japan). And the screen-printing mask was fabricated by Sefar Inc. (Depew, NY, USA). After patterning, the silver ink was cured at $120^{\circ} \mathrm{C}$ for $15 \mathrm{~min}$. The sensor was composed of two resistive sensing sections; the left section detected the SARS-CoV-2 virus, and the right section served as a control electrode. Both sections contain two interdigitated electrodes whose fingers were separated by $0.3 \mathrm{~mm}$ (Figure 3a). 
a)
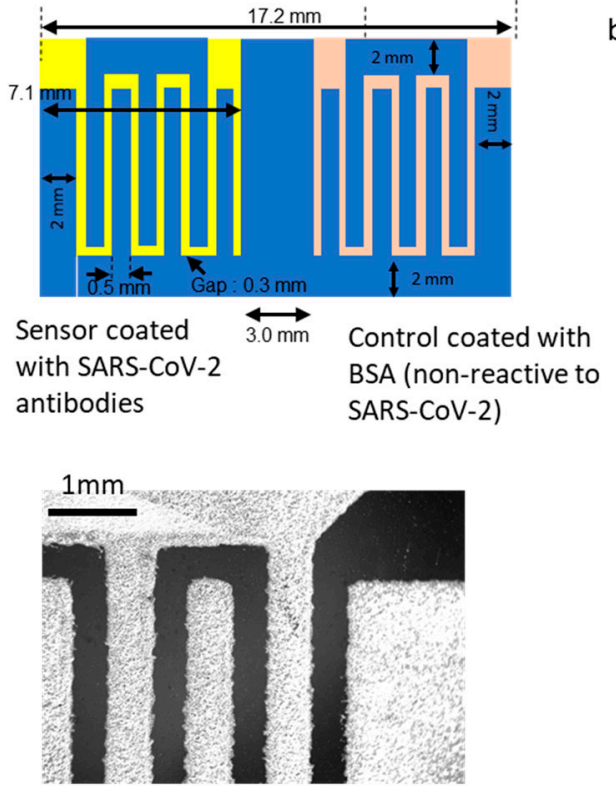

b)

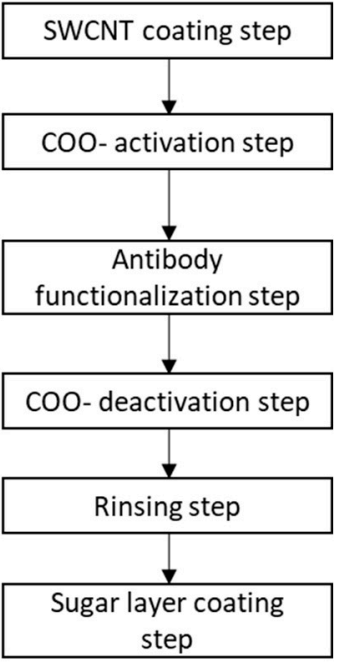

c)

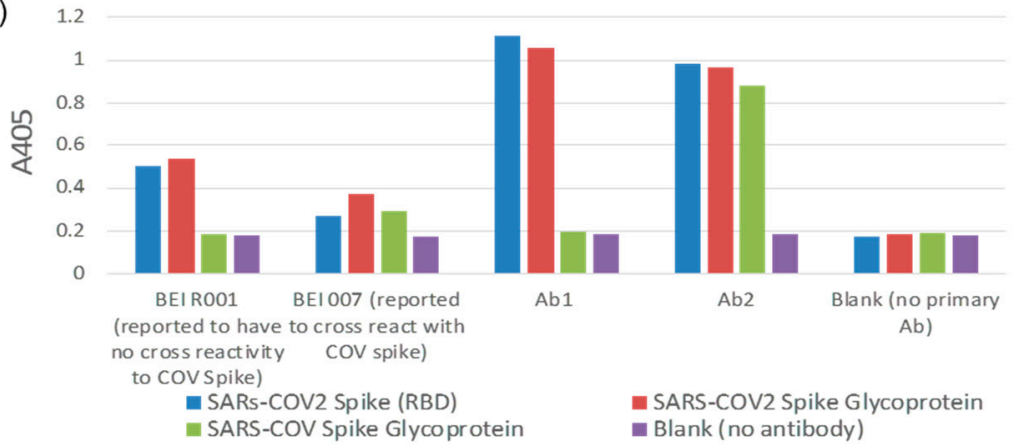

Figure 3. (a) Sensor configuration. Sensor electrodes are coated with SARS-CoV-2 antibodies. Control electrodes are with BSA. (b) Antibody functionalization step on SWCNTs. (c) Specificity test results to SARS-CoV and SARS-CoV-2 of antibodies using ELISA.

To covalently immobilize antibodies onto the SWCNT-COOH, a protocol was modified from the reference [34] to activate carboxyls on the SWCNT for covalently bonding to amino groups on antibodies (Figure 3b). A solution of $38.5 \mathrm{mg} / \mathrm{mL}$ EDC (Thermo \#22980) and $11 \mathrm{mg} / \mathrm{mL}$ S-NHS (Thermo \#PG8-2071) in DI water was prepared. $60 \mu \mathrm{L}$ of this solution was pipetted onto each side of the sensor and incubated for $15 \mathrm{~min}$ at room temperature. Sensors were then washed with DI water from a wash bottle and dried with a stream of air from a compressor. A $20 \mu \mathrm{g} / \mathrm{mL}$ solution of either virus-specific antibody or BSA was then added ( left side $=80 \mu \mathrm{L} \mathrm{Ab}$, right side $=80 \mu \mathrm{LBSA}$ ) and incubated at room temperature for $2 \mathrm{~h}$. Sensors were then rinsed with DI water and dried with a stream of air from a compressor. To quench any remaining amine-reactive groups, the $\mathrm{pH}$ was raised to 8.0 to speed hydrolysis. This was done by adding $300 \mu \mathrm{L}$ PBS ( $\mathrm{pH} 8$ ) to cover both sides of each sensor and incubating overnight at room temperature. Sensors were then rinsed with DI water and dried with a stream of air from a compressor. A layer of a trehalose and dextran mixture was added to protect the antibody surface during storage. Each sensor was dipped in a trehalose/dextran solution [2.5\% trehalose, $2.5 \%$ dextran (average MW 500,000)] [35] to cover the lower $2 / 3$ of the sensing area. Sensors were then cured for $2 \mathrm{H}$ in a $37^{\circ} \mathrm{C}$ incubator. In the following tests, all the sensors were stored at room temperature and used within one week. 


\subsection{Antibody Characterization}

We compared four commercial antibodies for binding to spike protein of both SARS$\mathrm{CoV}$ and SARS-CoV-2. Antibody cross-reactivity was measured to SARS-CoV-2 whole spike protein (BEI NR-52308), SARS-CoV-2 receptor-binding domain (RBD) section of spike protein (Sino Biological 40592-V05H), and SARS coronavirus whole spike (S) Protein (BEI NR-722).

For this experiment, two antibodies were previously tested for cross-reactivity with both SARS-CoV and SARS-CoV-2 spike protein (both whole and RBD). Sino Biological 40150-R007 has been previously shown to be specific to the SARS-CoV-2 spike S1 domain and spike receptor-binding domain (RBD) and has also shown to be cross-reactive with the SARS-CoV Spike S1 domain and RBD. Sino Biological 40150-R001 was specific to the SARS-CoV-2 spike protein RBD as shown previously in ELISA, with cross-reactivity to the SARS-CoV-2 spike $\mathrm{S} 1$ protein. However, cross-reactivity was not observed in ELISA with S1 glycoproteins from SARS-CoV.

Protein binding plates (Immulon 2HB, ThermoFisher Scientific 3455) were coated with $100 \mu \mathrm{L}$ of a $2 \mu \mathrm{g} / \mathrm{mL}$ antigen (spike protein) solution for $24 \mathrm{H}$ at room temperature. Following antigen binding, plates were washed w/DPBS from a wash bottle and then blocked with a $1 \mathrm{mg} / \mathrm{mL}$ BSA solution in DPBS $(200 \mu \mathrm{L})$ and incubated for $30 \mathrm{~min}$ at $37^{\circ} \mathrm{C}$. After washing excess BSA from the plate with DPBS from a wash bottle, a solution of the primary antibody ( $100 \mu \mathrm{L}$ of $1 \mu \mathrm{g} / \mathrm{mL}$ in DPBS) was added and incubated for $30 \mathrm{~min}$ at $37^{\circ} \mathrm{C}$. The plate was then washed with DPBS, and a $100 \mu \mathrm{L}$ of anti-rabbit conjugated HRP (Invitrogen 31460) at a 1:2000 dilution was added and incubated at $37^{\circ} \mathrm{C}$. After $30 \mathrm{~min}$, the excess secondary antibody was removed by washing with DPBS, then $100 \mu \mathrm{L}$ ABTS substrate (ThermoFisher 37615) was added and incubated for $10 \mathrm{~min}$ at room temperature. The plate was then read for absorbance on a microplate reader at A405nm.

The ELISA results showed the specific binding of BEI R001 and Ab1 to SARS-CoV-2 whole spike and RBD, while Ab2 shows additional cross-reactivity to SARS-CoV whole spike protein (Figure 3c).

\subsection{Sensor Characterization}

The sensor resistance change was characterized for sensors with and without antibodies. According to our observations, the functionalization step to activate and deactivate carboxyl groups on the SWCNT surface dominated the sensor resistance change. After the carboxyl groups were activated, the sensor resistance change was not consistent. By comparing the resistance change of sensors with and without antibodies, deactivation steps could be modified to result in a predictable change of SWCNT resistances. The resistance values for each step were measured as shown in Table 1. By considering the resistance change of the sensor without antibodies as a control, the functionalization protocol for the sensors with antibodies was optimized. The resistance change was compared for each step. For the comparison tests, $1 \mathrm{~mL}$ of $1 \times \mathrm{PBS}$ was used as the target solution with $1.1 \mathrm{~mL}$ of DI water. In addition, an initial test was conducted to study the resistance ratio change for $1 \times$ PBS, and $1 \times$ PBS spiked with SARS-CoV-2 (1000 genome equivalents $/ \mathrm{mL})$.

\subsection{Sensitivity Tests}

To test the sensitivity, various concentrations of inactivated SARS-CoV-2 [BEI \#NR52287 (Irradiated, Novel Coronavirus, 2019-nCoV/USA-WA1/2020)] were suspended in PBS buffer. The SARS-CoV-2 source consisted of the cell lysate and supernatant from Cercopithecus aethiops kidney epithelial cells infected with SARS-CoV-2. The virus was gammairradiated for inactivation. The initial concentration from BEI resources was $1.7 \times 10^{9}$ genome equivalents $/ \mathrm{mL}$. The initial stock solution was serially diluted to 10 particles $/ \mathrm{mL}$ by serial 10 fold dilutions. A $1 \mathrm{~mL}$ solution of the prepared virus sample was loaded into a sample cup. After the initial resistance measurement, an SWCNT sensor was dipped in DI water, followed by air-drying and the 2nd resistance measurement. The SWCNT sensor was then immersed in $1 \mathrm{~mL}$ of a virus solution for $10 \mathrm{~min}$ with an agitation $(3 \mathrm{~mm} / \mathrm{s})$, 
followed by an air-dry and the first washing. Two more dipping, air drying, and washing steps were repeated to measure all resistance changes. Based on the initial resistance value, all the normalized resistance values were calculated for data processing. For the control experiments, $1 \times$ PBS buffer without target virus was used.

\subsection{Test Using Nasal Swab Samples}

To evaluate the lower limit of detection for SARS-CoV-2, nasal swab samples were collected from deidentified healthy volunteers. After the complete drying of swabs for a few hours in air, the swab samples were immersed in $1 \mathrm{~mL}$ PBS for $1 \mathrm{~min}$ with gentle stirring. Subsequently, $500 \mu \mathrm{L}$ of the target analyte (SARS-CoV-2) in PBS was mixed with $500 \mu \mathrm{L}$ of the eluted swab solution. The $1 \mathrm{~mL}$ solution was used to test the LLD. The spiked concentrations of SARS-CoV-2 ranged from $10^{2}$ to $10^{5}$ genome equivalents $/ \mathrm{mL}$ in steps of 10-fold dilutions. The resistance values were measured and processed as previously described.

Additional sensitivity tests were conducted for the SARS-CoV-2 concentrations of 100, 250,500 , and 1000 genome equivalents / $\mathrm{mL}$ in order to estimate LOD. Based on the results, a linear analysis was conducted to estimate the accurate detection limit.

\subsection{Cross-Reactivity Test}

For cross-reactivity study, the response for SARS-CoV-2 $\left(10^{3}\right.$ genome equivalents $\left./ \mathrm{mL}\right)$ was compared with Staphylococcus Epidermidis (S. Epi at $10^{3} \mathrm{CFU} / \mathrm{mL}$ ), Mycobacterium Tuberculosis (MTB at $10^{3} \mathrm{CFU} / \mathrm{mL}$ ), and Staphylococcus Aureus (SA) at $10^{3} \mathrm{CFU} / \mathrm{mL}$, respiratory syncytial virus (RSV, $10^{6}$ genome equivalents $/ \mathrm{mL}$ ) and influenza $\mathrm{A}\left(\mathrm{H} 1 \mathrm{~N} 1,10^{6}\right.$ genome equivalents $/ \mathrm{mL}$ ). The nontargeted samples were suspended in $1 \times \mathrm{PBS}$, which was mixed with nasal swab samples. Each sample was repeated three times $(\mathrm{N}=3)$.

\subsection{Test Using Clinical Samples}

To validate the assay performance, 12 positive and 10 negative patient samples were tested from previously determined RT-qPCR assayed samples. The samples were collected by anterior nares swabs for the Husky Coronavirus Testing research study (IRB) that provided testing to faculty, staff, and students at the University of Washington in Seattle, WA, USA (PMID: 34805425). Dry samples were transported and eluted in $1 \mathrm{~mL}$ Tris-EDTA (PMID: 34286830 ) and stored at $-80^{\circ} \mathrm{C}$. Among the samples, 12 positive and 10 negative samples were randomly chosen and deidentified for sensor testing. The positive samples included alpha and delta variants of SARS-CoV-2. The sample collection and testing procedure were approved by the institutional review board (IRB) at the University of Washington (Husky Testing number: STUDY00011148).

Since the collected sample volume after RT-qPCR assays was only $100 \mu \mathrm{L}$, the sample was diluted to $1 \mathrm{~mL}$ using $1 \times$ PBS. The $1 \mathrm{~mL}$ samples were tested by the prepared SWCNT sensors in a non-blinded fashion. RT-qPCR Ct values were determined after thawing and dilution to serve as a direct comparator to the SWCNT.

The clinical testing lab was approved for SARS-CoV-2 screening assay based on RTqPCR [36]. The Northwest Genomics Center (NWGC) SwabDirect SARS-CoV-2 detection assay was validated for the workflow of COVID-19 screening. The sensitivity, specificity, accuracy, and precision of an extraction-free protocol were validated through the evaluation of the contrived positive specimens along with known positive and negative clinical specimens.

\section{Results and Discussion}

\subsection{Sensor Characterization}

When the sensor was fabricated without antibodies, the average resistance values were $9.88 \pm 1.51 \mathrm{k} \Omega(\mathrm{N}=12)$. When the antibodies were immobilized on the sensor surface, the average resistance values increased to $24.5 \pm 2.69 \mathrm{k} \Omega$. The normalized difference between the sensor and control resistances was $0.037 \pm 0.010$ for the sensors immobilized without 
antibodies $(\mathrm{N}=6)$. The normalized difference between the sensor and control resistances was $-0.057 \pm 0.061$ for the sensors with immobilized antibodies $(\mathrm{N}=6)$. Before antibody immobilization, the normalized resistance difference between sensing and control electrodes was positive. After antibody immobilization, the normalized resistance difference changed to a negative value due to the difference between SARS-CoV-2 antibodies and BSA on the electrodes.

To study the resistance change for the sensors with and without antibodies, both sensors were tested by the analyzer using the screening protocol (Figure 4). For this experiment, $1 \times$ PBS was used without any target analytes. As described in Table 1 , the initial resistance values $\left(R_{0}\right)$ were collected from the sensor $\left(R_{0 \_s}\right)$ and control $\left(R_{0 \_}\right)$electrodes. The initial resistance values served as a baseline for the following measurements. Figure $4 \mathrm{a}, \mathrm{b}$ show $P_{i \_s}$ and $P_{i \_c}$ value changes and their ratio change $P_{i}(i=0,1,2,3$, and 4$)$ for the sensors without antibodies. The normalized resistances of $P_{i_{-} s}$ and $P_{i_{c} c}$ were close to 1 at the prewash step in DI water, followed by an increase at the first rinsing step. The increase of the normalized resistance values was caused by the ion adsorption on the surface when the sensor was immersed in $1 \times$ PBS. The normalized resistance values decreased at the second and third rinsing steps as the ions were depleted in DI water.

Figure $4 c, d$ present the $P_{i \_s}$ and $P_{i \_c}$, and $P_{i}$ value changes with antibodies, respectively. With immobilization of antibodies, the prewash values of $P_{1 \_s}$ and $P_{1 \_c}$ reduced to 0.67 , but the overall trend was similar to the sensors without antibodies. The $\mathrm{P}_{\mathrm{i}}$ value showing the relative change ratio between the sensing and control electrodes showed an increased response at the first wash. The $\mathrm{P}_{3}$ and $\mathrm{P}_{4}$ values corresponding to the second and third rinsing showed a trend converging to 1 . According to the initial characterization, the trend for the $P_{i}$ values with and without antibodies approached 1 with multiple rinsing steps. 

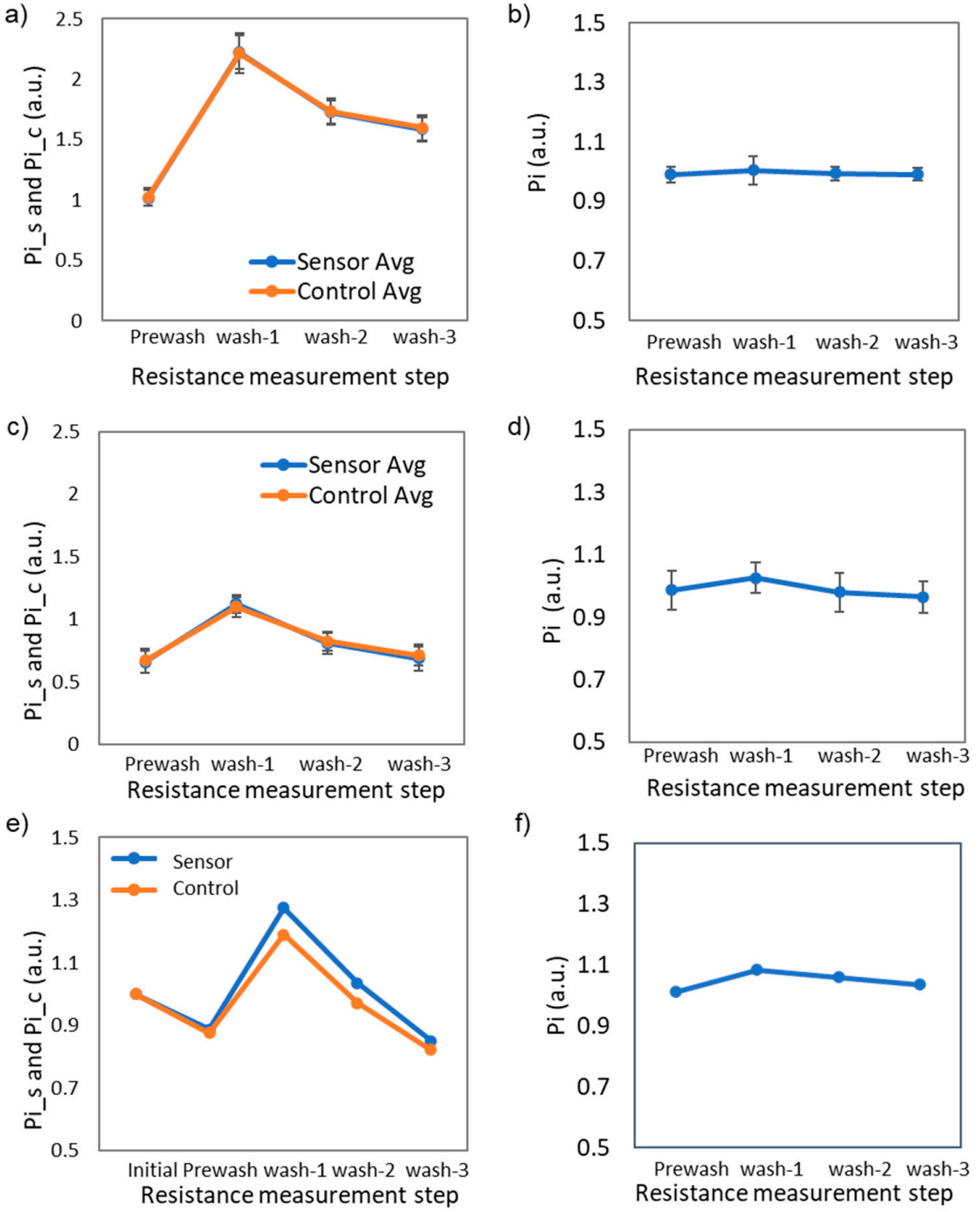

f)
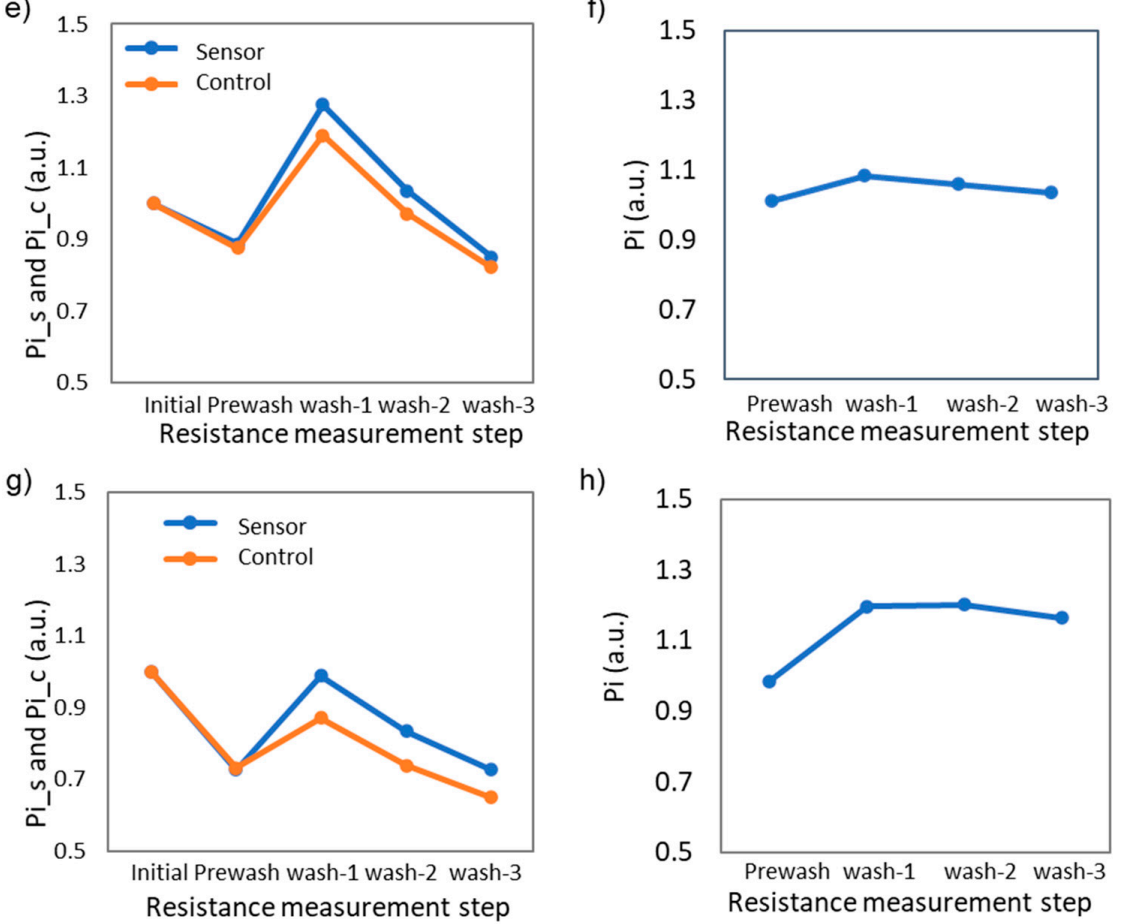

Figure 4. (a) $P_{i_{\_} s}$ and $P_{i_{\_} c}$ changes for the sensors without antibodies $(N=6)$. (b) $P_{i}$ changes for the sensors without antibodies $(\mathrm{N}=6)$. (c) $P_{i_{s} s}$ and $P_{i_{\_} c}$ changes for the sensors with antibodies $(N=6)$. (d) $P_{i}$ changes for the sensors with antibodies $(\mathrm{N}=6)$. (e) $P_{i_{\_} s}$ and $P_{i_{-} c}$ changes for the antibodyimmobilized sensors for a negative nasal swab sample. (f) $P_{i}$ changes for the antibody-immobilized sensors for a negative nasal swab sample. (g) $P_{i_{\_} s}$ and $P_{i_{\_} c}$ changes for the antibody-immobilized sensors for a negative nasal swab sample spiked with SARS-CoV-2 $\left(10^{3}\right.$ genome equivalents $\left./ \mathrm{mL}\right)$. (h) $\mathrm{P}_{\mathrm{i}}$ changes for the antibody-immobilized sensors for a negative nasal swab sample spiked with SARS-CoV-2 $\left(10^{3}\right.$ genome equivalents $\left./ \mathrm{mL}\right)$.

Table 2 shows one example of the measured resistance values for sensing and control electrodes. The resistance values were converted to the resistance ratio in Figure 4c. If 
the sensor resistance was greater than $40 \mathrm{kOhm}$, the sensor was not used due to an unpredictable sensitivity. If the resistance was lower than $10 \mathrm{kOhm}$, the SWCNTs were too abundant to achieve adequate sensitivity.

Table 2. Resistance values for negative control shown in Figure 4c.

\begin{tabular}{ccc}
\hline & Sensor $(\mathbf{k} \Omega)$ & Control (k $\mathbf{)})$ \\
\hline Initial resistance & 23.368 & 24.048 \\
pre-wash & 13.140 & 13.115 \\
wash 1 & 24.239 & 23.551 \\
wash 2 & 16.822 & 17.075 \\
wash 3 & 13.518 & 14.379 \\
\hline
\end{tabular}

An example of the resistance change ratios for the negative control in a nasal swab sample is shown in Figure $4 \mathrm{e}, \mathrm{f}$. The $\mathrm{P}_{\mathrm{i} \_s}$ and $\mathrm{P}_{\mathrm{i}_{\mathrm{c}} \mathrm{c}}$ values for sensing and control electrodes appeared to diverge more than pure PBS solution (Figure $4 \mathrm{e}$ ), but the $\mathrm{P}_{\mathrm{i}}$ values between sensor and control remained close to 1 (Figure $4 \mathrm{f}$ ). Figure $4 \mathrm{~h}$ are examples of the resistance changes for the positive control of $10^{3}$ genome equivalents $/ \mathrm{mL}$ in nasal swab samples. When the target viruses were captured on the sensor surface, the $P_{i_{-} s}$ and $P_{i_{\_} c}$ became larger at the rinsing steps (Figure $4 \mathrm{~g}$ ). The $P_{i}$ values clearly showed the difference between sensing and control electrodes in Figure $4 \mathrm{~h}$. In comparison to the negative control signal in Figure $4 \mathrm{f}$, the positive control signal in Figure $4 \mathrm{~h}$ showed the normalized value $>1$ due to the resistance change difference for sensing and control electrodes.

\subsection{Signal Processing and Sensitivity Tests}

Before the dose-response tests in nasal swab samples, the $P_{i}$ value changes were monitored for negative and positive nasal swab samples to determine the signal processing methods for screening. Figure $5 \mathrm{a}, \mathrm{b}$ show the $\mathrm{P}_{\mathrm{i}}$ values for negative swab samples and positive swab samples spiked with $10^{3}$ genome equivalents/mL-SARS-CoV-2 $(\mathrm{N}=6)$, respectively. Overall, the $\mathrm{P}_{2}, \mathrm{P}_{3}$, and $\mathrm{P}_{4}$ values of the positive samples were greater than those of negative samples. However, the $P_{i}$ values were not clearly differentiated in certain cases, which was attributed to sensor production batches and potential errors in washing steps. It was interesting to find that the positive signals showed a larger slope of $\mathrm{P}_{\mathrm{i}}$ between prewash $\left(\mathrm{P}_{1}\right)$ and the first wash $\left(\mathrm{P}_{2}\right)$. Also, the positive signals showed a lower average slope of $\left(\mathrm{P}_{2}-\mathrm{P}_{3}\right)$ and $\left(\mathrm{P}_{3}-\mathrm{P}_{4}\right)$. According to the results, we defined two parameters to determine the positive screening results as described in the following conditions.

$$
\begin{aligned}
& \text { If }\left(P_{2}-P_{1}\right)>0.12 \text {, a score of } C_{1}=0.5 \text { is given. } \\
& \text { If }\left(P_{4}-P_{1}\right)>0.1 \text {, a score of } C_{2}=0.5 \text { is given. }
\end{aligned}
$$




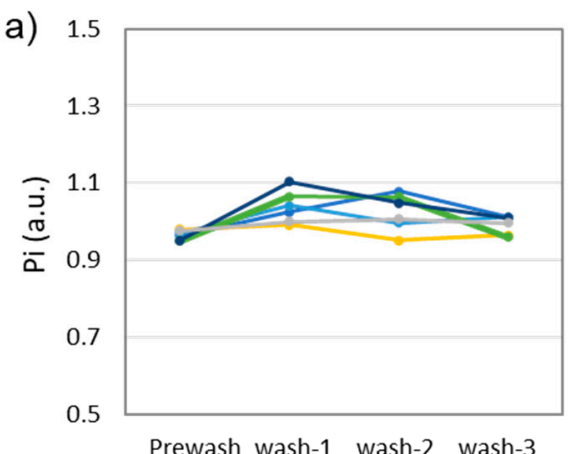

Resistance measurement step

C)

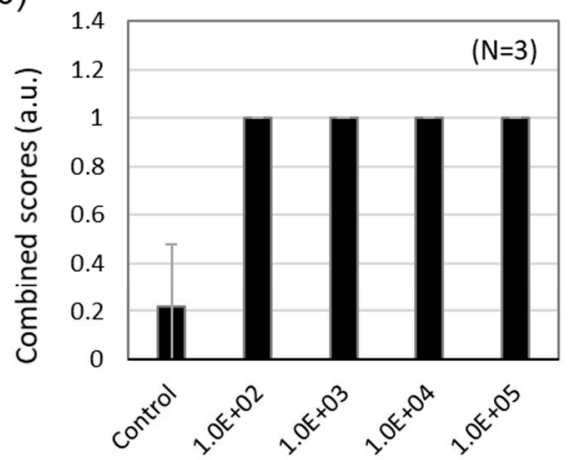

SARS-CoV-2 concentrations in PBS

(Genome equivalents $/ \mathrm{mL}$ )

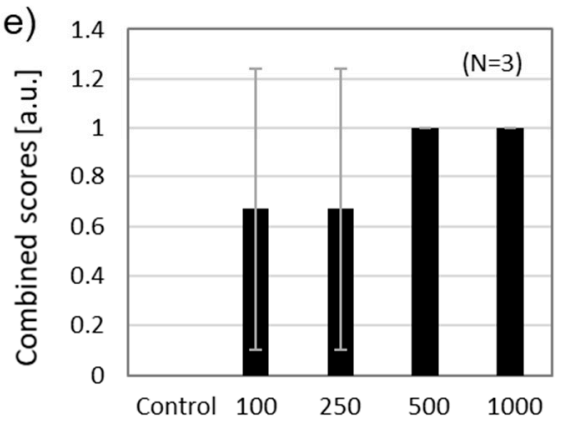

SARS-CoV-2 concentrations in nasal swab samples [Genome equivalents $/ \mathrm{mL}$ ] b)

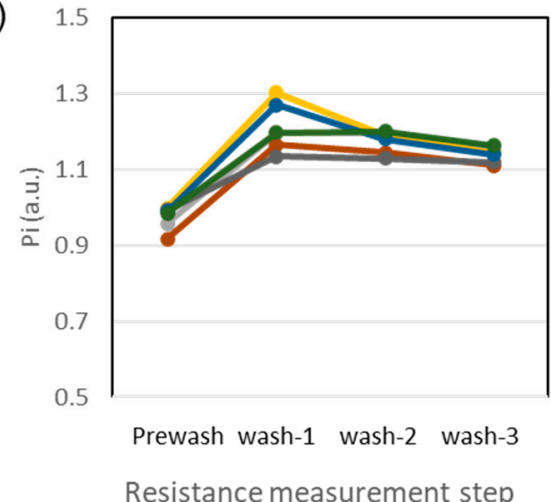

d)

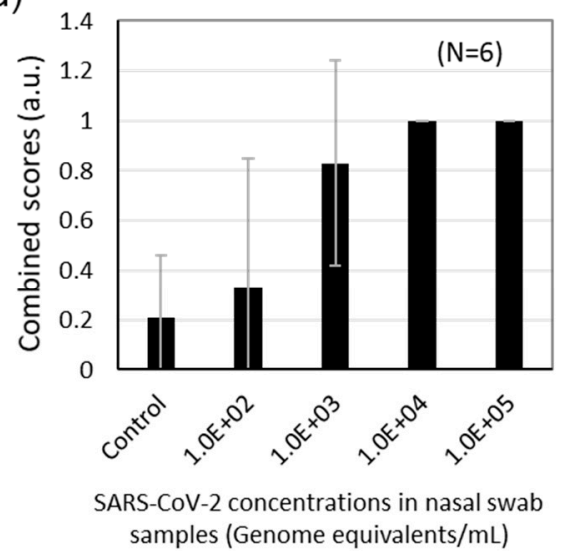

f)

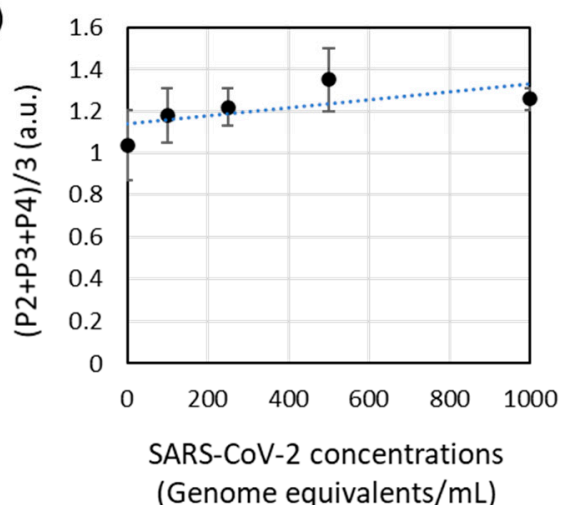

Figure 5. (a) Pi changes for negative nasal swab samples $(\mathrm{N}=6)$. (b) Pi changes for nasal swab samples spiked with SARS-CoV-2 (1000 genome equivalents $/ \mathrm{mL})$. ( $\mathrm{N}=6)(\mathrm{c})$ Combined scores for various concentrations of SARS-CoV-2 in $1 \times$ PBS $(N=3)$. Negative control $(N=9)(d)$ Combined scores for various concentrations of SARS-CoV-2 in nasal swab samples ( $\mathrm{N}=6$ for positive samples, $\mathrm{N}=12$ for negative controls). (e) Dose response tests for estimating the limit of detection in nasal swab samples spiked with SARS-CoV-2. The concentrations of SARS-CoV-2 are 0, 100, 250, 500, and 1000 genome equivalents/mL $(\mathrm{N}=3)$. (f) Average values of P2, P3, and P4 for the SARS-CoV-2 at the concentrations of $0,100,250,500$, and 1000 genome equivalents $/ \mathrm{mL}$ in nasal swab samples $(\mathrm{N}=3)$.

If the combined score of $C_{1}+C_{2}$ was equal to 1 , it was positive. If the combined scores were 0 or 0.5 , it was negative.

Using the combined scores, the dose response tests of SARS-CoV-2 in PBS were conducted. Figure $5 c$ shows the combined scores for SARS-CoV-2 in PBS at the concentrations of $10^{2}$ and $10^{5}$ genome equivalents $/ \mathrm{mL}$. All the signals of the positive samples showed the combined value of 1 . When the nasal swab samples spiked with $10^{2}$ and $10^{5}$ genome 
equivalents $/ \mathrm{mL}$ were used, two out of six samples showed the combined value of 1 at $10^{2}$ genome equivalents $/ \mathrm{mL}$, and five out of six samples showed the combined value of 1 at $10^{3}$ genome equivalents $/ \mathrm{mL}$ (Figure $5 \mathrm{~d}$ ).

To estimate the LLD in nasal swab samples, further testing was conducted for the SARS-CoV-2 concentrations of 100, 250, 500, and 1000 genome equivalents / mL (Figure 5e). At concentrations of 100 and 250, only one sensor out of three showed the combined score of 1 . The combined scores at 500 and 1000 genome equivalents $/ \mathrm{mL}$ were $1(\mathrm{~N}=3)$. When the average values of $\mathrm{P}_{2}, \mathrm{P}_{3}$, and $\mathrm{P}_{4}$ were used, the linear increase of the resistance ratio was observed (Figure $5 \mathrm{f}$ ). Based on the linear approximation of the average $\mathrm{P}_{\mathrm{i}}$ values, the LOD was 350 genome equivalents/mL. The LOD of 350 genome equivalents $/ \mathrm{mL}$ was better than typical nucleic amplification-based assays being used for COVID-19 screening. Given that swab samples were replete with human cell fragments, bacteria, and other interferents, these results also demonstrated the specificity of the developed SWCNT sensors.

The average value at 1000 genome equivalents $/ \mathrm{mL}$ in Figure $5 \mathrm{f}$ was a little lower than those of other concentrations, which could be caused by the different fabrication batches. Among the dataset, all the sensors except those used for 1000 genome equivalents $/ \mathrm{mL}$ were from the same batch. Note that the $\mathrm{P}_{2}$ value was the parameter that was conventionally used for screening using SWCNT sensors. Due to the batch-to-batch variation, the analog value of the resistance ratio could not be used directly. Instead, the combined scores were better for determining the positive and negative screening results.

\subsection{Cross-Reactivity Test}

Figure 6 shows the testing of cross-reactivity of the SWCNTs sensors. The nasal swab samples spiked with S. epidermidis, MTB, H1N1, RSV, and S.a. were used for negative samples and showed no response. The positive samples were nasal swab samples spiked with $10^{3}$ genome equivalents/mL-SARS-CoV-2, S. epidermidis, MTB, H1N1, RSV , and SA. The combined scores clearly showed the difference between negative and positive samples.

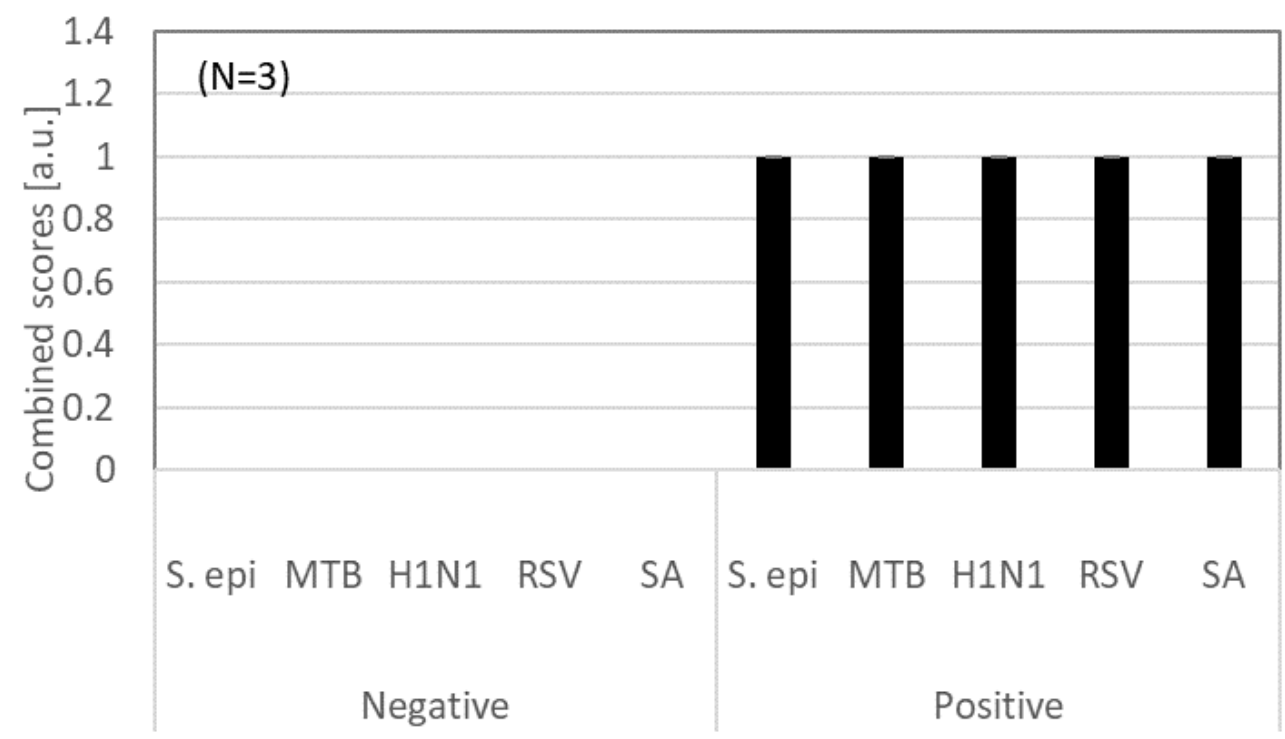

Figure 6. Combined scores for negative and positive nasal swab samples spiked with $\mathrm{S}$. epidermidis, MTB, H1N1, RSV, and SA. The concentration of SARS-CoV-2 was $10^{3}$ genome equivalents $/ \mathrm{mL}$. The bacterial concentrations of $S$. epidermidis, MTB, and S. $a$ were $10^{6} \mathrm{CFU} / \mathrm{mL}$. The viral concentrations of H1N1 and RSV were $10^{8}$ genome equivalents $\mathrm{mL}(\mathrm{N}=3)$.

\subsection{Clinical Sample Test Results}

Clinical testing was performed on previously frozen SARS-CoV2 positive and negative samples collected in TE buffer and tested with RT-PCR. Since only $100 \mu \mathrm{L}$ of the samples were available in TE buffer, the positive and negative samples were diluted 10-fold using 
$1 \times$ PBS. The PCR test results showed that the positive samples included alpha and delta variants. Among the twelve positive and ten negative samples, an SWCNT sensor showed one false positive result for a negative sample. According to the results, the clinical sensitivity was $100 \%$, and the clinical specificity was $90 \%$ (Table 3 ).

Table 3. Comparison of PCR results and SWCNT sensor results for positive and negative clinical samples (N/A means $\mathrm{Ct}>40)$.

\begin{tabular}{|c|c|c|c|c|c|c|}
\hline \multirow{2}{*}{$\begin{array}{c}\text { Positive } \\
\text { Sample ID }\end{array}$} & \multicolumn{2}{|c|}{ Reference PCR } & \multirow{2}{*}{$\begin{array}{l}\text { * SWCNT } \\
\text { Sensor }\end{array}$} & \multirow{2}{*}{$\begin{array}{c}\text { Negative } \\
\text { Sample ID }\end{array}$} & \multirow{2}{*}{$\begin{array}{c}\text { Reference PCR } \\
\text { Ct Value }(>40)\end{array}$} & \multirow{2}{*}{$\begin{array}{l}\text { * SWCNT } \\
\text { Sensor }\end{array}$} \\
\hline & Ct Value & Variants & & & & \\
\hline XXXX61b & 22.5 & alpha & Positive & XXXX8ba7 & $\mathrm{N} / \mathrm{A}$ & Negative \\
\hline XXXXa4dc & 33 & alpha & Positive & 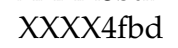 & $\mathrm{N} / \mathrm{A}$ & Negative \\
\hline$X X X X f 041$ & 23.5 & alpha & Positive & XXXX6ea9 & $\mathrm{N} / \mathrm{A}$ & Negative \\
\hline XXXX89d7 & 30 & alpha & Positive & XXXXa467 & $\mathrm{N} / \mathrm{A}$ & Negative \\
\hline XXXX996 & 29.4 & alpha & Positive & XXXXd9ee & $\mathrm{N} / \mathrm{A}$ & Negative \\
\hline XXXXa320 & 38.5 & alpha & Positive & XXXX297e & $\mathrm{N} / \mathrm{A}$ & Negative \\
\hline XXXX1b27 & 31.3 & delta & Positive & XXXX4907 & $\mathrm{N} / \mathrm{A}$ & ** Positive \\
\hline XXXXf10e & 30.6 & delta & Positive & XXXXde69 & $\mathrm{N} / \mathrm{A}$ & Negative \\
\hline$X X X X 8 c 9 c$ & 26.5 & delta & Positive & XXXX07e3 & $\mathrm{N} / \mathrm{A}$ & Negative \\
\hline XXXXf06c & 31.2 & alpha & Positive & $\mathrm{XXXX4d9f}$ & $\mathrm{N} / \mathrm{A}$ & Negative \\
\hline XXXX5456 & 30.4 & delta & Positive & & & \\
\hline $\mathrm{XXXX76fb}$ & 23.5 & alpha & Positive & & & \\
\hline
\end{tabular}

${ }^{*}$ Unblinded trial. ${ }^{* *}$ A PCR negative sample shows the strong positive signal of the SWCNT sensor. The sample collection and testing procedure has been approved by the institutional review board (IRB) at the University of Washington (Husky Testing number: STUDY00011148). The sample IDs are deidentified with XXXX.

\section{Conclusions}

In summary, an immunoresistive SWCNT sensor was developed to specifically detect SARS-CoV-2 in nasal swab samples. The analytical LOD was 350 genome equivalents $/ \mathrm{mL}$ with a detection time of $15 \mathrm{~min}$. The analytical LOD was better than point-of-care screening nucleic acid detection assays. In comparison to other antigen detection assays, the detection limit was 2 3 orders of magnitude more sensitive (Figure 7). To achieve such high sensitivity and specificity, the relative resistance change of an SWCNT sensor was measured in comparison to a control sensor. To improve the clinical sensitivity and specificity, a combined score using two parameters based on the resistance ratio was used. According to clinical sample tests, the assay showed $100 \%$ sensitivity and $90 \%$ specificity. The SWCNT sensors detected both alpha and delta variants. The simple resistive measurement will allow rapid screening by minimally trained personnel. Also, a minimal power requirement $(<1 \mathrm{~W})$ will be important for point-of-care (POC) screening in limited-resource settings. 


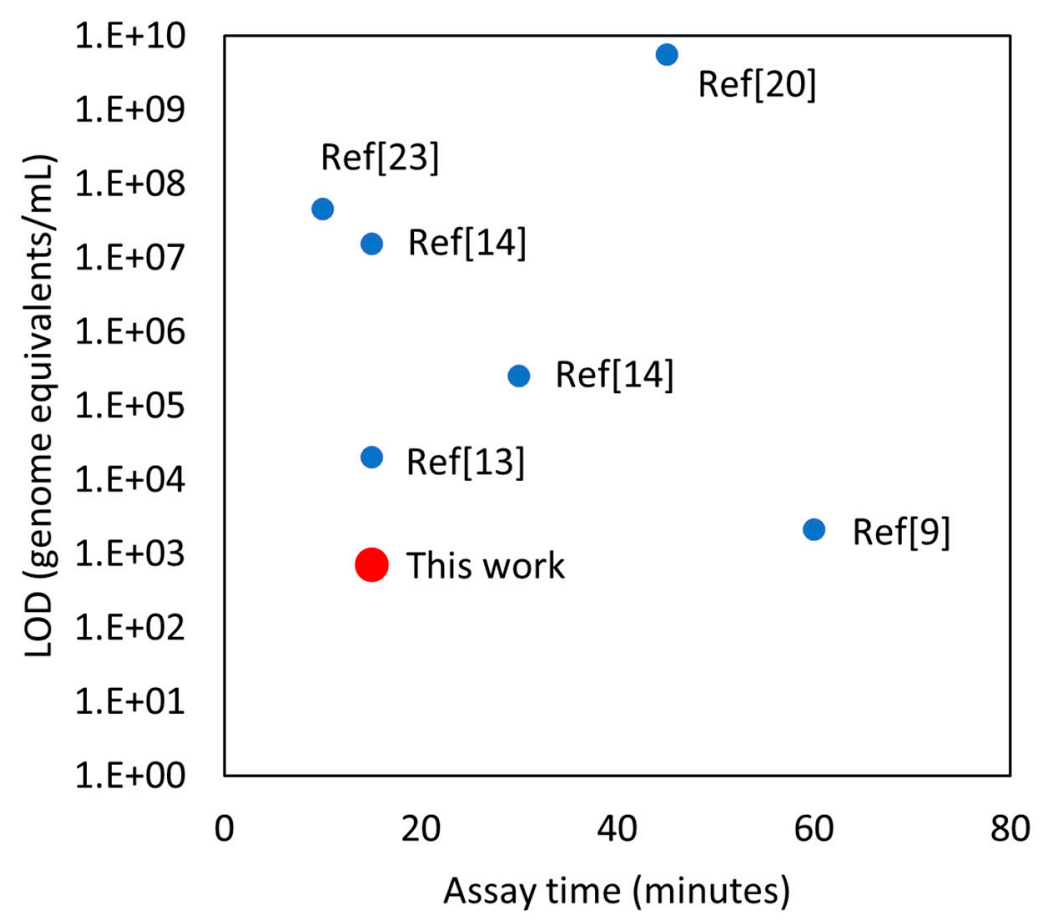

Figure 7. Comparison between this sensor and prior reports in terms of assay time and limit of detection (LOD). Several assumptions have been made to unify the units of LOD. Each virus contains 2 RNA strands. $1 \mathrm{PFU} / \mathrm{mL}$ is assumed to be $10,000 \mathrm{RNA}$ copies $/ \mathrm{mL}$ [37]. One virus is assumed to have 24 Spike Glycoprotein (S) and each of them has a mass of $100 \mathrm{kDa}$ [38]. In reference [7], the reported time is the response time instead of the assay time.

Regarding the analyzer and assay cost, the analyzer was constructed using massproduced parts to reduce the manufacturing cost. The assay cost was very low due to the plastic film patterned with silkscreened silver electrodes and antibodies. The fabrication yield of the SWCNT sensors was $\sim 70 \%$. The quality control process needs to be improved for a higher fabrication yield. Currently, we are developing a larger scale production of sensors with a quality management system included.

Author Contributions: Conceptualization (J.-H.C.); methodology (T.L., S.D.S., Z.T., V.S., S.-g.A., P.D.H.); software (T.L., Z.T.); data curation (T.L., S.D.S., J.-H.C.); formal analysis (C.E.F., J.-H.K., L.M.S., J.-H.C.); writing (T.L., S.D.S., J.-H.K., J.-H.C.); edit (T.L., C.E.F., J.-H.K., L.M.S., J.Z., J.-H.C.); visualization (T.L., S.-g.A., J.-H.K., J.-H.C.); investigation (T.L., S.D.S., J.-H.C.); resources (C.E.F., S.-g.A., L.M.S., J.Z., J.-H.C.); supervision (C.E.F., L.M.S., J.-H.C.); funding acquisition and project administration (J.-H.C.). All authors have read and agreed to the published version of the manuscript.

Funding: We acknowledge the support by WE-REACH foundation (U01HL152401-S2; WR-20-041-Dx) as a part of an NIH RADx program (project number: 2640).

Institutional Review Board Statement: The sample collection and testing procedure were approved by the institutional review board (IRB) at the University of Washington (Husky Testing number: STUDY00011148).

Informed Consent Statement: Not applicable.

Data Availability Statement: Not available.

Acknowledgments: We appreciate Rodney Ho (Director of WE-REACH), Stephen Flaim (Senior Advisor at NIH), Young-Hoon Kwon (UW Medicine), and Xiaohu Gao (UW BioEngineering) for advice on assay development and optimization.

Conflicts of Interest: The authors declare no conflict of interest. 


\section{References}

1. Coronavirus Disease (COVID-2019) Situation Reports. Available online: https://www.cmim.org/PDF_covid/Coronavirus_ disease2019_COVID-19_UpToDate2.pdf (accessed on 2 January 2022).

2. Pokhrel, P.; Hu, C.P.; Mao, H.B. Detecting the Coronavirus (COVID-19). ACS Sens. 2020, 5, 2283-2296. [CrossRef] [PubMed]

3. Seshadri, D.R.; Davies, E.V.; Harlow, E.R.; Hsu, J.J.; Knighton, S.C.; Walker, T.A.; Voos, J.E.; Drummond, C.K. Wearable Sensors for COVID-19: A Call to Action to Harness Our Digital Infrastructure for Remote Patient Monitoring and Virtual Assessments. Front. Digit. Health 2020, 2, 8. [CrossRef]

4. Kumar, S.S.; Dashtipour, K.; Abbasi, Q.H.; Imran, M.A.; Ahmad, W. A Review on Wearable and Contactless Sensing for COVID-19 With Policy Challenges. Front. Commun. Netw. 2021, 2, 636293. [CrossRef]

5. Gupta, N.; Augustine, S.; Narayan, T.; O’Riordan, A.; Das, A.; Kumar, D.; Luong, J.H.T.; Malhotra, B.D. Point-of-Care PCR Assays for COVID-19 Detection. Biosensors 2021, 11, 141. [CrossRef] [PubMed]

6. Ulinici, M.; Covantev, S.; Wingfield-Digby, J.; Beloukas, A.; Mathioudakis, A.G.; Corlateanu, A. Screening, Diagnostic and Prognostic Tests for COVID-19: A Comprehensive Review. Life 2021, 11, 561. [CrossRef]

7. Interim Guidance for Antigen Testing for SARS-CoV-2. Available online: https://www.cdc.gov/coronavirus/2019-ncov/lab/ resources/antigen-tests-guidelines.html (accessed on 5 February 2022).

8. Kubina, R.; Dziedzic, A. Molecular and Serological Tests for COVID-19. A Comparative Review of SARS-CoV-2 Coronavirus Laboratory and Point-of-Care Diagnostics. Diagnostics 2020, 10, 434. [CrossRef] [PubMed]

9. Chow, F.W.N.; Chan, T.T.Y.; Tam, A.R.; Zhao, S.H.; Yao, W.M.; Fung, J.; Cheng, F.K.K.; Lo, G.C.S.; Chu, S.; Aw-Yong, K.L.; et al. A Rapid, Simple, Inexpensive, and Mobile Colorimetric Assay COVID-19-LAMP for Mass On-Site Screening of COVID-19. Int. J. Mol. Sci. 2020, 21, 5380. [CrossRef] [PubMed]

10. Iravani, S. Nano- and biosensors for the detection of SARS-CoV-2: Challenges and opportunities. Mater. Adv. 2020, 1, 3092-3103. [CrossRef]

11. Giovannini, G.; Haick, H.; Garoli, D. Detecting COVID-19 from Breath: A Game Changer for a Big Challenge. ACS Sens. 2021, 6, 1408-1417. [CrossRef]

12. FDA. BinaxNOW COVID-19 Antigen Self Test-Letter of Authorization. Available online: https://www.fda.gov/media/147251 /download (accessed on 6 January 2021).

13. Perchetti, G.A.; Huang, M.L.; Mills, M.G.; Jerome, K.R.; Greninger, A.L. Analytical Sensitivity of the Abbott BinaxNOW COVID-19 Ag Card. J. Clin. Microbiol. 2021, 59, 3. [CrossRef]

14. Corman, V.M.; Haage, V.C.; Bleicker, T.; Schmidt, M.L.; Muhlemann, B.; Zuchowski, M.; Jo, W.K.; Tscheak, P.; Moncke-Buchner, E.; Muller, M.A.; et al. Comparison of seven commercial SARS-CoV-2 rapid point-of-care antigen tests: A single-centre laboratory evaluation study. Lancet Microbe 2021, 2, E311-E319. [CrossRef]

15. Wolfel, R.; Corman, V.M.; Guggemos, W.; Seilmaier, M.; Zange, S.; Muller, M.A.; Niemeyer, D.; Jones, T.C.; Vollmar, P.; Rothe, C.; et al. Virological assessment of hospitalized patients with COVID-2019. Nature 2020, 581, 465-469. [CrossRef] [PubMed]

16. Benda, A.; Zerajic, L.; Ankita, A.; Cleary, E.; Park, Y.; Pandey, S. COVID-19 Testing and Diagnostics: A Review of Commercialized Technologies for Cost, Convenience and Quality of Tests. Sensors 2021, 21, 6581. [CrossRef] [PubMed]

17. FDA. Antibody Testing Is Not Currently Recommended to Assess Immunity after COVID-19 Vaccination: FDA Safety Communication. Available online: https://www.fda.gov/medical-devices/safety-communications/antibody-testing-not-currentlyrecommended-assess-immunity-after-covid-19-vaccination-fda-safety (accessed on 21 February 2022).

18. Abdelhamid, H.N.; Badr, G. Nanobiotechnology as a platform for the diagnosis of COVID-19: A review. Nanotechnol. Environ. Eng. 2021, 6, 19. [CrossRef]

19. Seo, G.; Lee, G.; Kim, M.J.; Baek, S.H.; Choi, M.; Ku, K.B.; Lee, C.S.; Jun, S.; Park, D.; Kim, H.G.; et al. Rapid Detection of COVID-19 Causative Virus (SARS-CoV-2) in Human Nasopharyngeal Swab Specimens Using Field-Effect Transistor-Based Biosensor. ACS Nano 2020, 14, 5135-5142. [CrossRef]

20. Mojsoska, B.; Larsen, S.; Olsen, D.A.; Madsen, J.S.; Brandslund, I.; Alatraktchi, F.A. Rapid SARS-CoV-2 Detection Using Electrochemical Immunosensor. Sensors 2021, 21, 390. [CrossRef]

21. Yakoh, A.; Pimpitak, U.; Rengpipat, S.; Hirankarn, N.; Chailapakul, O.; Chaiyo, S. Paper-based electrochemical biosensor for diagnosing COVID-19: Detection of SARS-CoV-2 antibodies and antigen. Biosens. Bioelectron. 2021, 176, 112912. [CrossRef]

22. Hashemi, S.A.; Behbahan, N.G.G.; Bahrani, S.; Mousavi, S.M.; Gholami, A.; Ramakrishna, S.; Firoozsani, M.; Moghadami, M.; Lankarani, K.B.; Omidifar, N. Ultra-sensitive viral glycoprotein detection NanoSystem toward accurate tracing SARS-CoV-2 in biological/non-biological media. Biosens. Bioelectron. 2021, 171, 112731. [CrossRef]

23. Moitra, P.; Alafeef, M.; Dighe, K.; Frieman, M.B.; Pan, D. Selective Naked-Eye Detection of SARS-CoV-2 Mediated by N Gene Targeted Antisense Oligonucleotide Capped Plasmonic Nanoparticles. ACS Nano 2020, 14, 7617-7627. [CrossRef]

24. Huang, L.P.; Ding, L.F.; Zhou, J.; Chen, S.L.; Chen, F.; Zhao, C.; Xu, J.Q.; Hu, W.J.; Ji, J.S.; Xu, H.; et al. One-step rapid quantification of SARS-CoV-2 virus particles via low-cost nanoplasmonic sensors in generic microplate reader and point-of-care device. Biosens. Bioelectron. 2021, 171, 112685. [CrossRef]

25. Asghari, A.; Wang, C.; Yoo, K.M.; Rostamian, A.; Xu, X.C.; Shin, J.D.; Dalir, H.; Chen, R.T. Fast, accurate, point-of-care COVID-19 pandemic diagnosis enabled through advanced lab-on-chip optical biosensors: Opportunities and challenges. Appl. Phys. Rev. 2021, 8, 031313. [CrossRef] [PubMed] 
26. Byon, H.R.; Choi, H.C. Network single-walled carbon nanotube-field effect transistors (SWNT-FETs) with increased Schottky contact area for highly sensitive biosensor applications. J. Am. Chem. Soc. 2006, 128, 2188-2189. [CrossRef] [PubMed]

27. Li, C.; Curreli, M.; Lin, H.; Lei, B.; Ishikawa, F.N.; Datar, R.; Cote, R.J.; Thompson, M.E.; Zhou, C.W. Complementary detection of prostate-specific antigen using $\ln 2 \mathrm{O} 3$ nanowires and carbon nanotubes. J. Am. Chem. Soc. 2005, 127, 12484-12485. [CrossRef] [PubMed]

28. Heller, I.; Janssens, A.M.; Mannik, J.; Minot, E.D.; Lemay, S.G.; Dekker, C. Identifying the mechanism of biosensing with carbon nanotube transistors. Nano Lett. 2008, 8, 591-595. [CrossRef]

29. Allen, B.L.; Kichambare, P.D.; Star, A. Carbon nanotube field-effect-transistor-based biosensors. Adv. Mater. 2007, 19, 1439-1451. [CrossRef]

30. Lee, D.J.; Chander, Y.; Goyal, S.M.; Cui, T.H. Carbon nanotube electric immunoassay for the detection of swine influenza virus H1N1. Biosens. Bioelectron. 2011, 26, 3482-3487. [CrossRef]

31. Wasik, D.; Mulchandani, A.; Yates, M.V. A heparin-functionalized carbon nanotube-based affinity biosensor for dengue virus Biosens. Bioelectron. 2017, 91, 811-816. [CrossRef]

32. Singh, R.; Sharma, A.; Hong, S.; Jang, J. Electrical immunosensor based on dielectrophoretically-deposited carbon nanotubes for detection of influenza virus H1N1. Analyst 2014, 139, 5415-5421. [CrossRef]

33. Kahng, S.; Soelberg, S.; Fongdjo, F.; Kim, J.; Furlong, C.E.; Chung, J.-H. Carbon nanotube-based thin-film resistive sensor for point-of-care screening of tuberculosis. Biomed. Microdevices 2020, 22, 50. [CrossRef]

34. Hermanson, G.T. Bioconjugate Techniques; Elsevier Inc.: Amsterdam, The Netherlands, 2013.

35. Stevens, R.C.; Soelberg, S.D.; Eberhart, B.T.L.; Spencer, S.; Wekell, J.C.; Chinowsky, T.M.; Trainer, V.L.; Furlong, C.E. Detection of the toxin domoic acid from clam extracts using a portable surface plasmon resonance biosensor. Harmful Algae 2007, 6, 166-174. [CrossRef]

36. Srivatsan, S.; Heidl, S.; Pfau, B.; Martin, B.K.; Han, P.D.; Zhong, W.Z.; van Raay, K.; McDermot, E.; Opsahl, J.; Gamboa, L.; et al. SwabExpress: An End-to-End Protocol for Extraction-Free COVID-19 Testing. Clin. Chem. 2022, 68, 143-152. [CrossRef] [PubMed]

37. Sender, R.; Bar-On, Y.M.; Gleizer, S.; Bernshtein, B.; Flamholz, A.; Phillips, R.; Milo, R. The total number and mass of SARS-CoV-2 virions. Proc. Natl. Acad. Sci. USA 2021, 118, e2024815118. [CrossRef] [PubMed]

38. Ke, Z.L.; Oton, J.Q.; Qu, K.; Cortese, M.; Zila, V.; McKeane, L.; Nakane, T.; Zivanov, J.; Neufeldt, C.J.; Cerikan, B.; et al. Structures and distributions of SARS-CoV-2 spike proteins on intact virions. Nature 2020, 588, 498-502. [CrossRef] [PubMed] 